\title{
Avaliação do gerenciamento de resíduos sólidos através do Sistema de Indicadores de Sustentabilidade Pressão-Estado-Impacto-Reposta (PEIR) no Município de Cachoeira dos Índios, Estado da Paraíba, Nordeste do Brasil
}

\section{Thayse da Silva Lima ${ }^{1}$ e José Deomar de Souza Barros ${ }^{2}$}

${ }^{1}$ Universidade Federal de Campina Grande (UFCG). Centro de Formação de Professores. Grupo de Pesquisa Ambiental para o Desenvolvimento do Semiárido (GPA). Rua Sérgio Moreira de Figueiredo, s/no. Casas Populares. Cajazeiras-PB, Brasil (58900-000).

${ }^{2}$ Universidade Federal de Campina Grande (UFCG). Centro de Formação de Professores. Grupo de Pesquisa Ambiental para o Desenvolvimento do Semiárido (GPA). Rua Sérgio Moreira de Figueiredo, s/no. Casas Populares. Cajazeiras-PB, Brasil (58900-000). E-mail: deomarbarros@gmail.com.

Resumo. 0 crescimento da população e consequente aumento da produção e consumo, aliados ao uso desenfreado dos recursos naturais, tem originado diversos fatores que afetam o meio ambiente, dentre estes se destaca o grande número de resíduos sólidos gerados, os quais, sem um gerenciamento adequado, pode ocasionar impactos negativos ao meio ambiente. Nesta perspectiva, esta pesquisa objetivou avaliar o gerenciamento dos resíduos sólidos na Cidade de Cachoeira dos Índios, Estado da Paraíba, Nordeste do Brasil, desenvolvida entre 6 de junho e 21 de outubro de 2018, sendo entrevistados 49 atores sociais e institucionais. Para a coleta de dados utilizou-se questionários e observações da coleta, transporte e local de disposição dos resíduos sólidos urbanos. $\mathrm{Na}$ análise dos dados foi utilizada a abordagem quali-quantitativa, avaliando o gerenciamento de resíduos sólidos como "favorável" ou "desfavorável", do ponto de vista da sustentabilidade, por meio do sistema de indicadores de sustentabilidade Pressão-Estado-Impacto-Resposta (PEIR). Os resultados indicam que o município avaliado não dispõe de um aterro sanitário, sendo os resíduos sólidos depositados em lixão a céu aberto. Desta forma, o gerenciamento não se encontra de acordo com o estabelecido na Política Nacional de Resíduos Sólidos, tendo a gestão municipal e a população civil pouco conhecimento sobre a problemática dos resíduos sólidos. Dos 31 indicadores, 24 foram avaliados como desfavoráveis do ponto de vista da sustentabilidade. Estes dados revelam uma situação preocupante quanto à sustentabilidade do município, que necessita da implementação de políticas públicas voltadas para um gerenciamento adequado dos resíduos sólidos urbanos.

Recebido $25 / 07 / 2019$

Aceito

$22 / 12 / 2019$

Publicado

$31 / 12 / 2019$

Acesso aberto

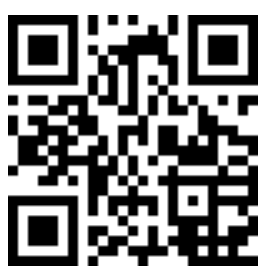

ORCID

(1) 0000-0003-4555-9791 Thayse da Silva Lima

(D) 0000-0003-3785-9823 José Deomar de Souza Barros 
Palavras-chave: Meio ambiente; Resíduos sólidos; Gerenciamento; Sustentabilidade.

\begin{abstract}
Evaluation of solid waste management using pressure-state-impact-response system of sustainability indicators in the municipality of Cachoeira dos Índios, State of Paraíba, Northeast Brazil. The growth of the population, consequent increase in production and consumption and the unbridled use of natural resources has given rise to diverse factors that affect the environment, such as the large amount of solid waste generated, which, without adequate management, can have negative impacts on the environment. Therefore, the aim of the present study was to evaluate solid waste management in the City of Cachoeira dos Índios, State of Paraíba, Brazil. The study was developed between June 6th and October 21st, 2018 and involved interviews with 49 social and institutional actors. Data were collected with the use of questionnaires and observations of the collection, transport and dumping site of urban solid waste. Data analysis involved the use of a quali-quantitative approach, evaluating solid waste management based on the pressure-stateimpact-response system of sustainability indicators. Each indicator was evaluated as either "favorable" or "unfavorable" from the standpoint of sustainability. The results indicate that the city has no landfill and the solid waste is deposited in an open-air dump. Therefore, management is not in compliance with the National Solid Waste Policy and both the managers and civil population have little knowledge regarding the solid waste problem. Among the 31 indicators investigated, 24 were evaluated as unfavorable from the standpoint of sustainability. The present data reveal a worrisome situation with regard to the sustainability of the municipality, which needs the implementation of public policies directed at the adequate management of urban solid waste.
\end{abstract} Keywords: Environment; Solid waste; Management;
Sustainability.

\section{Introdução}

O crescimento da população e consequente aumento da produção e consumo, aliados a um uso desenfreado dos recursos naturais, tem originado diversos fatores que afetam o meio ambiente, dentre estes se destaca o grande número de resíduos sólidos produzidos, os quais, sem um gerenciamento adequado pode ocasionar impactos negativos ao meio ambiente.

Os resíduos sólidos estão diretamente ligados a problemas ambientais, destacando-se a poluição dos recursos naturais (solo, água e ar) e por consequência efeitos a saúde humana (Pedrosa e Nishiwak, 2014). 0 aumento na produção de resíduos sólidos, sobretudo nos grandes centros urbanos, é resultado das alterações no estilo de vida e modos de produção e consumo da população, em decorrência do desenvolvimento econômico, crescimento populacional, urbanização e a revolução tecnológica. Além do aumento na quantidade de resíduos gerados, atualmente estes passaram também 
a apresentar em sua composição elementos sintéticos e perigosos aos ecossistemas (Gouveia, 2012).

Em decorrência da necessidade de uma gestão adequada dos resíduos sólidos, foi instituída a Lei no 12.305 , de 2 de agosto de 2010 (Brasil, 2010), designada Política Nacional de Resíduos Sólidos (PNRS), visando a uma gestão integrada e um gerenciamento ambientalmente adequado dos resíduos sólidos. Tendo dentre os seus princípios uma visão sistêmica, considerando as variáveis ambiental, social, cultural, econômica, tecnológica e de saúde pública, bem como o desenvolvimento sustentável (Brasil, 2010). Segundo Lima (2014), os municípios precisam se reorganizar a fim de cumprir as determinações da PNRS, dessa forma devem partir de um estudo da atual situação, para então sugerir as necessárias alterações que possibilitem a implementação do PNRS.

A elaboração do Plano de Gerenciamento Integrado de Resíduos Sólidos é um dos fatores primordiais para a efetiva prática da PNRS por parte dos municípios. 0 mesmo refere-se a um planejamento estratégico, o qual deve ser elaborado coletivamente, incluindo a participação dos gestores públicos, do setor privado e da sociedade civil. Assim, é importante que os resíduos sólidos gerados sejam de responsabilidade de cada setor, permitindo que a gestão destes ocorra na prática de forma integrada (Cardoso et al., 2016).

Desta forma, apesar de ser inicialmente dever da gestão pública, é nítida a importância e necessidade de que a sociedade civil participe tanto do planejamento quanto da execução das propostas de gerenciamento dos resíduos, e que se responsabilize pelos resíduos gerados.

Como afirma Hanai (2009), os indicadores constituem-se em instrumentos uteis na análise objetiva sobre um determinado fenômeno, à medida que identificam características de relevância de um sistema e esclarecem as complexas relações entre as variáveis distintas envolvidas num fenômeno específico.

0 intenso debate sobre a problemática ambiental e sustentabilidade impulsionou o surgimento da metodologia PEIR. Inicialmente o modelo Pressão-Estado-Resposta (PER) foi proposto por um grupo de pesquisadores canadenses, sendo adotado como padrão de indicadores de sustentabilidade pela Organização para a Cooperação e Desenvolvimento Econômico (OECD) e pela Comissão das Nações Unidas para o Desenvolvimento Sustentável. Esse modelo baseia-se no conceito de casualidade e reflete as relações entre as ações humanas e a modificação do ambiente e de seus recursos naturais (Hanai, 2009).

Posteriormente o PER passou a ser utilizado pelo Programa das Nações Unidas para o Meio Ambiente (PNUMA), sendo ampliado para o PEIR (PressãoEstado-Impacto-Resposta) metodologia utilizada na presente pesquisa. Este último organiza melhor as variáveis, reconhecendo os impactos causados pela ação humana, que já ultrapassa os efeitos da poluição, fornecendo assim, um estudo completo da situação do manejo dos RSU (Moreira, 2016).

Portanto, esta pesquisa objetivou avaliar o gerenciamento dos resíduos sólidos no Município de Cachoeira dos Índios, no Estado da Paraíba, através do Sistema de Indicadores de Sustentabilidade Pressão-EstadoImpacto-Reposta (PEIR).

\section{Metodologia}

Esta pesquisa foi executada no Município de Cachoeira dos Índios, Estado da Paraíba, no período de 6 de junho a 21 de outubro de 2018.

\section{estudo \\ Caracterização da área de}

0 Município de Cachoeira dos Índios, com uma área de 193,068 km², possui cerca de 9.546 habitantes e está 
localizada no extremo oeste do Estado da Paraíba, pertencendo a área geográfica que abrange o semiárido brasileiro, distando cerca de $508 \mathrm{~km}$ da capital João Pessoa (IBGE, 2010).

\section{Classificação da pesquisa}

Do ponto de vista da sua natureza, esta pesquisa classifica-se como aplicada, objetivando gerar conhecimentos para a solução de problemas específicos e de interesse local. Do ponto de vista dos seus objetivos trata-se de uma pesquisa descritiva, a qual busca descrever as características de determinada população ou fenômeno, bem como o estabelecimento de relações entre variáveis, utilizando um padrão de técnicas para coleta de dados (Prodonov e Freitas, 2013).

Conforme a abordagem do problema, esta pesquisa possui características tanto quantitativa quanto qualitativa. Segundo Silva e Menezes
(2005), a pesquisa quantitativa admite que tudo pode ser quantificável, ou seja, traduzido em números. Enquanto a pesquisa qualitativa considera a relação existente entre o mundo real e o sujeito, a qual não pode ser quantificada.

Referente aos procedimentos técnicos trata-se de um estudo de caso, o qual envolve um estudo intenso que permite um vasto e minucioso conhecimento.

\section{Sujeitos da pesquisa}

Os sujeitos pesquisados foram os atores sociais e atores institucionais de diversos setores. Todos estes são importantes, visto que estão diretamente relacionados com a problemática em questão.

\section{População, amostra e amostra-} gem

A população, amostra e amostragem da pesquisa foi realizada conforme Tabela 1.

Tabela 1. População, amostra e amostragem da pesquisa.

\begin{tabular}{|l|c|}
\hline Atores sociais e institucionais & Número de entrevistados \\
\hline Representantes do poder público & 5 \\
\hline Representantes de escolas & 4 \\
\hline Moradores de bairros & 25 \\
\hline Agentes de limpeza & 5 \\
\hline Catadores & 2 \\
\hline Comerciantes & 5 \\
\hline Líderes sociais & 3 \\
\hline Total & $\mathbf{4 9}$ \\
\hline
\end{tabular}

Fonte: Adaptado de Moreira (2016).

\section{dados \\ Instrumentos de coleta de \\ Para a coleta de dados foram utilizados questionários, bem como realizadas observações da coleta, transporte e local de disposição final dos resíduos sólidos urbanos. A referida pesquisa foi aprovada pelo Comitê de Ética em Pesquisa (CEP), CAAE 90652918.5.0000.5575.}

\section{Análise dos dados}

$\mathrm{Na}$ análise dos dados utilizou-se uma abordagem quali-quantitativa, avaliando o gerenciamento de resíduos sólidos por meio do Sistema de Indicadores de Sustentabilidade PressãoEstado-Impacto-Resposta (PEIR). Os indicadores foram avaliados como "favorável" ou "desfavorável" do ponto de vista da sustentabilidade. 


\section{Resultados e discussão}

\section{pressão \\ Diagnóstico dos indicadores de \\ Para essa categoria foram} selecionados oito indicadores, os quais analisam a pressão das ações urbanas exercida ao ambiente.

\section{Coleta de lixo diretamente para}

o lixão. A Política Nacional de Resíduos Sólidos (PNRS), lei $\mathrm{n}^{\circ} 12.305$ de 2 de agosto de 2010, estabelece a necessidade de implantação de aterros sanitários no Brasil em substituição aos lixões a céu aberto como medida de proteção ao meio ambiente. Entretanto, como afirma Barbosa (2012), um grande problema no Brasil é justamente a quantidade de aterros sanitários, sendo a maioria dos resíduos depositados em lixões a céu aberto e descartados de qualquer forma.

Após coletados, os resíduos podem seguir três destinos: estações de transferência ou transbordo, espaços de processamento e recuperação, como processo de incineração e usinas de triagem e compostagem, ou serem direcionados para os locais de disposição final, como aterros e lixões (Cunha e Caixeta Filho, 2002).

De acordo com as observações realizadas e a constatação de todos os atores sociais e institucionais pesquisados, os resíduos sólidos produzidos no município de Cachoeira dos Índios são coletados e levados diretamente para o local de disposição, um vazadouro a céu aberto, popularmente conhecido como lixão. Portanto, este indicador é classificado como DESFAVORÁVEL à sustentabilidade do município, pela existência de lixão a céu aberto, em desacordo com o estabelecido pela PNRS.

Coleta de lixo nos bairros. Segundo Gouveia (2012), é definido como resíduo sólido, todo e qualquer resíduo domiciliar ou encontrado em via pública. Geralmente são restos de alimentos, embalagens de alimentos e de outros produtos, folhas e tantos outros resíduos descartados pela população.

Consoante Godecke et al. (2012), a quantidade de resíduos sólidos produzidos pelas populações não está relacionada unicamente com o nível de riqueza, refletido pela capacidade econômica de consumo. Os valores e hábitos de vida também determinam o grau de disposição para a realização do consumo.

Em Cachoeira dos Índios a coleta de resíduos nos bairros ocorre regularmente todos os dias, através da prestação de serviços de limpeza urbana de responsabilidade da gestão municipal. Desta forma, este indicador pode ser avaliado como FAVORÁVEL à sustentabilidade do município, tendo em vista que a disposição de resíduos pelas vias públicas pode representar um risco para a população em geral.

As etapas de gerenciamento realizadas no município são: a coleta direta dos resíduos nos bairros realizada pelos agentes de limpeza, o transporte em caçambas e a disposição final no vazadouro. 0 processo de manejo dos resíduos pelos agentes de limpeza nem sempre ocorre da maneira adequada, considerando as condições de trabalho, como equipamentos individuais, podendo representar riscos para esses profissionais.

\section{Queima de resíduos a céu} aberto. Conforme Lima et al. (2014), a incineração passa a ser empregada no Brasil como método de tratamento do lixo, tornando mais complexa a elaboração dos sistemas de gestão dos resíduos sólidos urbanos. 0 processo de incineração torna-se vantajoso à medida que reduz a quantidade de resíduos destinados aos aterros, desde que controladas as emissões poluentes provenientes de tal atividade.

0 processo de incineração de resíduos pode representar riscos à saúde humana, considerando as diversas substâncias tóxicas produzidas, entre estas gases, partículas, metais pesados e 
compostos orgânicos, que são emitidos na atmosfera. Assim, populações que residem próximas a locais de incineração, podem ser contaminadas de forma direta, através da inalação do ar contaminado, ou indireta, mediante o consumo de água ou alimentos contaminados, ou ainda pelo contato com o solo (Gouveia, 2012).

$$
\text { Dos } 49 \text { atores sociais }
$$

entrevistados, 33 confirmaram a ocorrência de queima dos resíduos no lixão a céu aberto, destacando a frequente ocorrência de incêndios na localidade (Figura 1). No entanto, a gestão municipal assegurou que essa atividade não ocorre por parte da administração pública. Dessa forma, acredita-se que seja de responsabilidade de terceiros e em algumas situações ocorra de forma espontânea. Independente dos responsáveis, a queima dos resíduos a céu aberto ocorre no município, caracterizando esse indicador como DESFAVORÁVEL à sustentabilidade, considerando ainda a possibilidade de pessoas e animais terem contato com o local, por ser de fácil acesso.

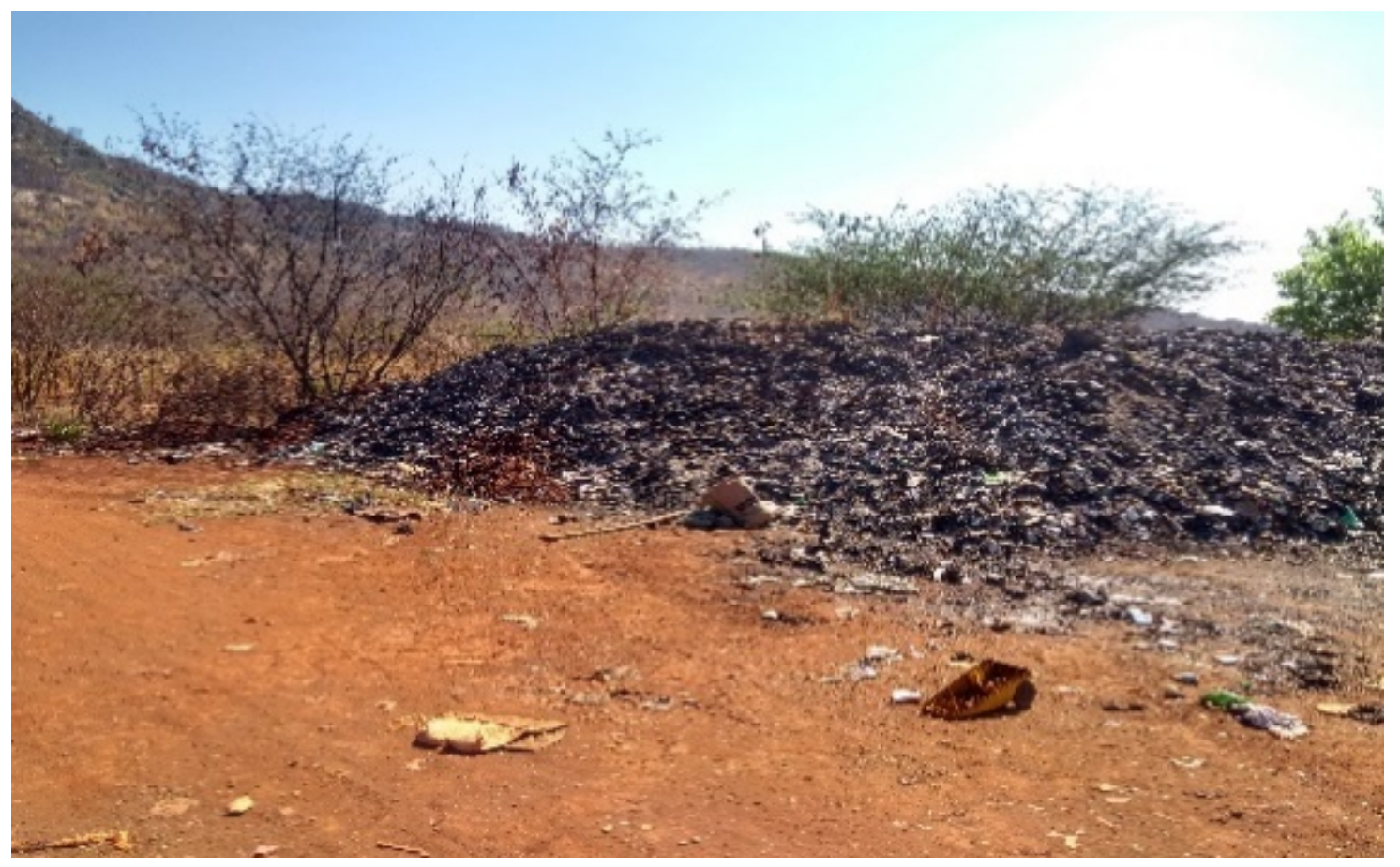

Figura 1. Resíduos queimados a céu aberto, no Município de Cachoeira dos Índios-PB, 2018.

Presença de animais na área de disposição. Locais como lixões a céu aberto, onde há a disposição de resíduos torna-se bastante propício à presença de animais. Na referida pesquisa verificouse na localidade de disposição dos resíduos sólidos a presença de urubus, bem como moscas e mosquitos, vetores de doenças, que são frequentemente comuns nesses ambientes.

Apesar de não ter sido encontrado durante as visitas outros tipos de animais, o local é acessível para a entrada destes. Dessa forma, foi constatada por grande parte dos entrevistados a ocorrência de animais no 
lixão, classificando este indicador como DESFAVORÁVEL, ao considerar os riscos decorrentes do contato de animais com essas localidades.

\section{Existência de moradias na} unidade. Em alguns centros urbanos, parte da população acaba se inserido nos lixões em busca de alimento e fonte de renda, decorrente da venda de materiais recicláveis encontrados no local (Pereira e Curi, 2013).

Apesar dos inúmeros riscos que os lixões impõem à saúde, os mesmos são ambientes comuns a moradia de pessoas que não possuem um lar, particularmente para os catadores autônomos, os quais retiram destes locais o sustento para sua sobrevivência, tendo assim, um baixo custo referente à moradia (Leite e Barros, 2019.)

0 vazadouro fica localizado relativamente próximo a um dos bairros da cidade, no entanto as moradias mais próximas tem uma distância admissível. Considerando assim, a inexistência de moradia no local de disposição, este indicador é avaliado como FAVORÁVEL à sustentabilidade do município.

Existência de catadores. Em consonância com Cavalcante et al. (2018), as condições precárias de trabalho dos catadores de materiais nestes locais são indicadores das vulnerabilidades as quais estes profissionais estão suscetíveis e que no entanto, não são vistas pela gestão pública e sociedade moderna.

Como destaca Hoefel et al. (2013), as queixas acerca dos lixões são decorrentes das condições de trabalho e riscos oferecidos nestes locais, incluindo riscos químicos, biológicos, físicos $\mathrm{e}$ ergonômicos. Nesse contexto, ainda que o uso de equipamentos de proteção individual (EPI) não solucione os empecilhos oriundos das condições precárias de trabalho, representam uma alternativa que contribui para a segurança desses trabalhadores, quando utilizados de forma adequada.

Segundo Gouveia (2012), esse grupo de trabalhadores, os quais atuam de maneira informal ou através de cooperativas, são protagonistas de um importante trabalho ambiental, que contribui de forma expressiva para o regresso de diversos materiais ao ciclo produtivo, fornecendo economia de energia e matéria-prima e interrompendo a disposição de inúmeros materiais em aterros.

No Município de Cachoeira dos Índios, constata-se a existência de catadores, que além de coletar materiais no local de disposição final dos resíduos, também realizam a coleta de materiais nas residências, especialmente nas zonas rurais, principalmente garrafas e objetos de alumínio. Em dias de festas, é mais frequente a prática de catadores, em razão da grande quantidade de materiais disponíveis. Assim, esse indicador é avaliado como DESFAVORÁVEL, tendo em vista a existência de catadores, em contato com ambiente insalubre e sem condições adequadas de trabalho.

\section{Destinação dos resíduos dos} serviços de saúde. Os resíduos dos serviços de saúde constituem uma pequena fração dos resíduos gerados em um município, estes necessitam de um tratamento e destinação diferenciada dos demais resíduos, tidos como perigosos à saúde pública, tendo em vista que possivelmente apresentam-se contaminados por patógenos (SOARES et al., 2018).

De acordo com Moreira (2016), os riscos dos resíduos de serviços de saúde (RSS) estão associados aos agentes patológicos comuns em ambientes hospitalares, como bactérias, fungos, vírus e protozoários, sendo a incineração o método mais utilizado em grandes fontes produtoras de RSS na eliminação de tais microrganismos.

Segundo a gestão municipal, os resíduos provenientes dos serviços de 
saúde recebem uma destinação diferenciada dos demais resíduos sólidos produzidos no município, sendo estes de responsabilidade de uma empresa contratada pela prefeitura, a qual realiza todo o processo de disposição dos mesmos. Dessa forma, esse indicador apresenta-se como FAVORÁVEL, pelo fato dos resíduos de saúde não serem depositados no vazadouro a céu aberto como ocorre com os demais resíduos.

Isolamento do local de disposição. A área de disposição final dos resíduos sólidos apresenta um cercamento, no entanto, este não impede a entrada de animais e pessoas, o que torna o local totalmente acessível. Sendo assim, esse indicador é avaliado como DESFAVORÁVEL do ponto de vista da sustentabilidade, por se tratar de um local vulnerável ao surgimento de vetores e a possível transmissão de doenças.

\section{Estado \\ Diagnóstico dos indicadores de}

Os indicadores de Estado avaliam as condições em que o ambiente se encontra, levando em consideração aspectos como a qualidade do ar e do solo, em decorrência da disposição dos resíduos sólidos.

Drenagem de gases. Como afirma Pereira e Curi (2013), a degradação ambiental é acentuada pela disposição inadequada dos resíduos sólidos urbanos, uma vez que essa disposição incorreta acarreta a poluição do solo, do ar e das águas subterrâneas, em decorrência da liberação de gases e do chorume advindos da decomposição da matéria orgânica.

Em concordância com Moreira (2016), um importante indicador da situação em que se encontra o meio ambiente é a qualidade do ar. Assim, a drenagem dos gases nos locais de destinação final dos resíduos é de grande relevância para a redução dos gases do efeito estufa, entre outros gases que podem ocasionar problemas a saúde humana.

Conforme Godecke et al. (2012), além dos impactos à saúde humana em decorrência de vetores existentes no lixões, poluição do ar, absorção de metais pesados e outros fatores, a atmosfera também é afetada, agravando o aquecimento global, à medida que gases provenientes da decomposição da matéria orgânica são concentrados.

o Município de Cachoeira dos Índios não dispõe de um aterro sanitário para a disposição final dos resíduos, sendo assim nenhum sistema de drenagem de gases é realizado, o que caracteriza esse indicador como DESFAVORÁVEL.

Aproveitamento de gases. Grandes quantidades de gases de efeito estufa (GEE) são gerados em decorrência da decomposição da matéria orgânica existente nos resíduos, particularmente o gás metano, considerado um dos responsáveis pelo aquecimento global. Como forma de redução desses gases, tem sido realizadas algumas iniciativas de captação do metano advindos de aterros sanitários e sua posterior utilização na produção de energia, no entanto essa atividade tem ocorrido em apenas uma pequena parcela do total de aterros sanitários existentes no Brasil (Gouveia, 2012).

Esse indicador classifica-se como DESFAVORÁVEL, ao constatar-se que no município de Cachoeira dos Índios não ocorre o aproveitamento de gases, já que os resíduos são depositados em um vazadouro a céu aberto.

Existência de instalações administrativas. De acordo com Moreira (2016), frequentemente em aterros sanitários observa-se a existência de instalações administrativas, as quais têm como finalidade a sistematização e organização do gerenciamento dos resíduos dispostos.

Tendo em vista que no referido município os resíduos não tem como 
destinação final um aterro sanitário, também não observa-se a presença de instalações administravas no local, o que classifica esse indicador como DESFAVORÁVEL.

Existência de base de impermeabilização. Em um sistema de aterro sanitário cada elemento que o compõe apresenta sua função, atuando como agentes na prevenção de prejuízos. Nisto, as técnicas de impermeabilização exercem papel na retenção dos contaminantes produzidos, sendo de grande importância para a redução de impactos ambientais (Locastro e Angelis, 2016).

Segundo Soares et al. (2017), apesar da disponibilidade de materiais de baixo custo no mercado e tantas tecnologias disponíveis atualmente, bases impermeabilizantes, que são elementos adequados para impedir o contato dos resíduos sólidos, tem sua implementação restrita apenas aos aterros sanitários.

Como já destacado, a localidade de disposição final dos resíduos sólidos no município de Cachoeira dos Índios é um vazadouro a céu aberto. Dessa forma, não ocorre a existência de base de impermeabilização, já que esse sistema limita-se a locais com aterros sanitários. Portanto esse indicador é tido como DESFAVORÁVEL para o município supramencionado.

\section{Cobertura dos resíduos sólidos.}

De acordo com 14 dos pesquisados, os resíduos depositados no vazadouro são cobertos por camadas de terra e segundo a gestão essa atividade ocorre mensalmente. Entretanto, esse processo não é realizado de forma adequada, ainda mais por tratar-se um vazadouro a céu aberto. Assim, ao considerar esses fatores, esse indicador pode ser classificado como DESFAVORÁVEL.

Drenagem do chorume. 0 chorume, líquido de cor escura e proveniente da decomposição da matéria orgânica, pode ser um contaminador do solo e das águas superficiais ou subterrâneas, em decorrência da contaminação do lençol freático (Gouveia, 2012).

Esse indicador pode ser avaliado como DESFAVORÁVEL, visto que no referido município não ocorre nenhum tipo de drenagem do chorume, podendo ocasionar prejuízos ao solo em decorrência desse conteúdo.

Tratamento do chorume. Uma alternativa viável para o tratamento do chorume é o aterro sanitário, que compreende um sistema de compactação dos resíduos sólidos em camadas, com base de impermeabilização, no qual o chorume é coletado e devidamente tratado, não ocasionando a contaminação das águas subterrâneas.

Como já mencionado, no município não há a existência de um aterro sanitário, ao passo que não ocorre a drenagem do chorume e por consequência também não existe sistema de tratamento para o mesmo. Diante disso, esse indicador também classificase como DESFAVORÁVEL do ponto de vista da sustentabilidade.

\section{Licenciamento ambiental. A} Política Nacional de Meio Ambiente estabelece dentre os seus instrumentos: o zoneamento ambiental, a avaliação de impactos ambientais e o licenciamento e a revisão de atividades efetiva ou potencialmente poluidoras (Brasil, 2010).

O licenciamento ambiental, então instituído pela Política Nacional de Meio Ambiente é um instrumento de fiscalização ambiental com o objetivo de prevenir impactos ambientais decorrentes de instalações ou quaisquer atividades que possam afetar negativamente $o$ ambiente $e$ seus recursos naturais. Conforme informações da gestão municipal, o local utilizado como disposição final dos resíduos no município de Cachoeira dos Índios não 
possui um licenciamento ambiental para a realização de tal atividade, configurando esse indicador como DESFAVORÁVEL.

Monitoramento ambiental. 0 monitoramento ambiental pode ser entendido como a observação e acompanhamento da situação dos recursos naturais, em decorrência das transformações antrópicas ou naturais, a fim de propor melhorias ou a preservação do ambiente.

No Município de Cachoeira dos Índios não verifica-se a realização de monitoramento ambiental, tendo em vista que os resíduos produzidos são destinados a um lixão a céu aberto, sem a devida preocupação com as consequências para o ambiente. Portanto esse indicador é avaliado como DESFAVORÁVEL à sustentabilidade do município.

\section{Impacto \\ Diagnóstico dos indicadores de}

Os indicadores de Impacto reconhecem os efeitos causados pela ação humana, que já ultrapassa os efeitos da poluição, fornecendo assim, um estudo completo da situação do manejo dos RSU (Moreira, 2016). Envolve fatores como a saúde e qualidade de vida da população.

Doenças envolvendo a população no entorno do lixão. Como destaca Cavalcante (2018), impactos negativos ocasionados ao meio ambiente podem levar a uma degradação ambiental e consequentemente afetar a saúde e qualidade de vida do ser humano. Consoante Gouveia (2012, p. 1509), as "decisões que envolvem o gerenciamento de resíduos sólidos urbanos são fundamentalmente decisões sobre saúde pública e requerem, portanto, a integração entre políticas econômicas, sociais e ambientais".

Conforme dados desta pesquisa, apesar da forma inadequada de destinação final dos resíduos não foi relatado a ocorrência de doenças envolvendo a população em decorrência da disposição dos resíduos no lixão. Assim, esse indicador classifica-se como FAVORÁVEL.

Poluição dos recursos hídricos. Mananciais de água potável, sejam superficiais ou subterrâneos, estão sujeitos a contaminação em decorrência dos resíduos sólidos tratados de forma indevida e depositados em vazadouros a céu aberto, aliado a isso a dispersão de doenças através de vetores que se proliferam em decorrência da presença de resíduos (SILVA et al., 2012b)

Considerando que os resíduos depositados no lixão não atingem cursos de água, consequentemente não acarretam a poluição desses recursos, podendo ser avaliado como FAVORÁVEL. Entretanto, a forma mais segura de impedir a contaminação de reservatórios de água seria a existência de uma base de impermeabilização, o que não ocorre em locais como o lixão.

Má utilização do espaço. 0 espaço utilizado para a disposição final dos resíduos no município de Cachoeira dos Índios representa uma área relativamente grande, na qual os resíduos são despejados sem uma organização aparente. Percebe-se então, que o espaço é mal utilizado, visto que o mesmo poderia ser reduzido se houvesse uma preocupação com essa disposição. Portanto, esse indicador avalia-se como DESFAVORÁVEL à sustentabilidade do município. 

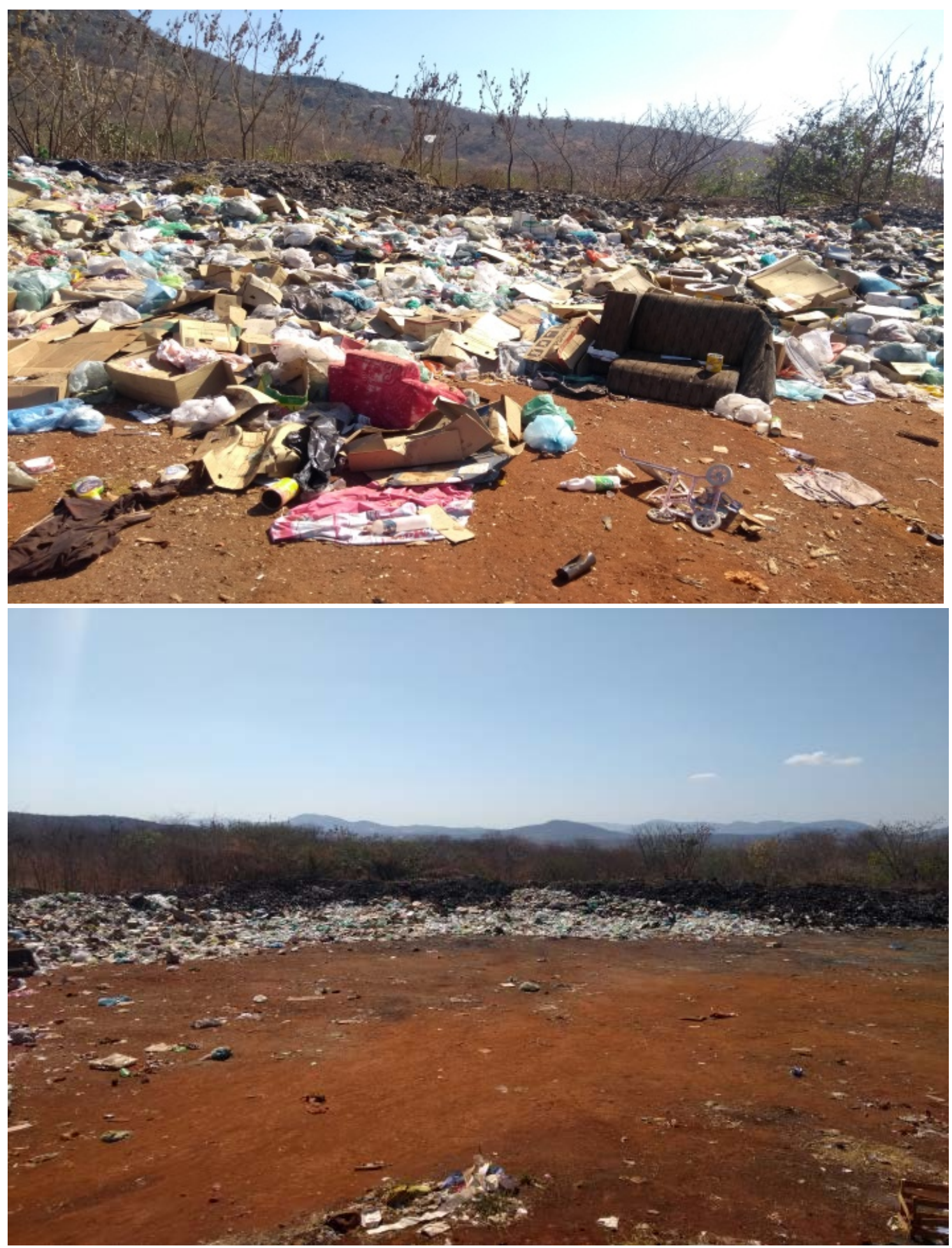

Figura 2. Espaço utilizado como disposição final dos resíduos, Município de Cachoeira dos Índios, 2018.

Paisagem da localidade. A disposição inadequada dos resíduos sólidos urbanos resulta em consequências para a população do entorno desses locais, no que se refere à poluição ambiental, o clima e a saúde 
humana. 0 bem estar das pessoas e a valorização dos imóveis nessas localidades são reduzidos, fator resultante do mau cheiro e da degradação da paisagem (Godecke et al., 2012).

A existência de um lixão a céu aberto é sinônimo de poluição visual. No referido município, apesar da distância considerável entre o local de disposição e o bairro mais próximo, é inegável o quanto a paisagem da localidade fica comprometida, ainda mais quando se considera o grande espaço utilizado como destinação dos resíduos, que são depositados de forma desordenada, ocupando uma área maior do que necessária. Portanto esse indicador classifica-se como DESFAVORÁVEL.

\section{Contaminação de animais} domésticos. A presença de animais em lixões representa uma situação de risco à saúde da população, tendo em vista que ao entrar em contato com esses locais e consumir resíduos, esses animais podem adquirir doenças, as quais podem atingir a população que tenham contato com estes (Leite e Barros, 2019).

Em razão da distância entre $o$ lixão e as moradias do bairro mais próximo, não foi constatado a presença e contaminação de animais domésticos, o que se avalia como FAVORÁVEL, visto que a contaminação desses animais afetaria também a população em geral.

Alagamento de vias públicas. Como enfatiza Moreira (2016), a disposição de resíduos em locais inadequados pode acarretar 0 alagamento de vias públicas e dispersão de lixo nas ruas, visto que em estações chuvosas, resíduos dispostos em terrenos baldios podem ser carregados até esgotos e bueiros, impossibilitando o escoamento da água advinda da chuva.

Conforme constatado durante a pesquisa, não há a ocorrência de alagamento das vias públicas no munícipio, que sejam decorrentes da disposição dos resíduos sólidos urbanos, avaliando esse indicador como FAVORÁVEL à sustentabilidade.

\section{Resposta}

Diagnóstico dos Indicadores de

Os indicadores de resposta buscam analisar o que tem sido realizado por parte da gestão e população em relação a problemática dos resíduos sólidos. Corresponde as ações realizadas com o intuito de evitar ou mitigar impactos negativos ao ambiente.

Existência de associação ou cooperativa de catadores. Em consonância com Cavalcante (2018), os catadores de materiais recicláveis estão frequentemente suscetíveis a inúmeros riscos, incluídos nestes os riscos ambientais. Mediante essa afirmação, fazse necessário a adoção de práticas que visem reduzir a exposição e constância desses riscos no ambiente de trabalho, buscando melhores condições de vida para esses profissionais.

Apesar da existência de catadores no município, constatou-se a inexistência de uma associação ou cooperativa responsável pela atuação desses profissionais, os quais atuam por conta própria, lidando com um ambiente insalubre, com péssimas condições de trabalho, vulneráveis a riscos de saúde. Sendo assim, esse indicador pode ser avaliado como DESFAVORÁVEL.

Tratamento de resíduos sólidos urbanos. De acordo com Cavalcante (2018), é de grande relevância o emprego de tecnologias para o tratamento dos resíduos sólidos urbanos. Entretanto, para um tratamento de fato adequado, deve ser considerada a gestão integrada destes, a partir da separação dos resíduos na fonte produtora chegando a sua disposição, assim o tratamento irá contribuir para a prevenção ou diminuição dos impactos negativos decorrente dos mesmos.

Em Cachoeira dos Índios, nenhuma forma de tratamento de 
resíduos tem sido executada, considerando que os mesmos são coletados e levados diretamente para a destinação final, a qual ocorre de forma inadequada, como exposto na PNRS. Diante disso, esse indicador avalia-se como DESFAVORÁVEL.

\section{Política pública para o} tratamento dos resíduos sólidos. É fundamental a existência de políticas públicas que sejam eficientes no gerenciamento dos resíduos, destacando assim, a importância da atuação do Estado perante a grande quantidade de resíduos gerados, viabilizando a reutilização desses resíduos e consequente retorno no processo produtivo (Silva e Lima, 2018).

Esse indicador avalia-se como DESFAVORÁVEL, visto que no município não verifica-se a existência de políticas públicas voltadas para o tratamento dos resíduos sólidos urbanos gerados.

\section{Atividades de educação} ambiental no município. Consoante Oliveira et al. (2018), é de fundamental importância a promoção de atividades de educação ambiental, desde o início do desenvolvimento escolar do cidadão, atuando como elemento fomentador na mudança de práticas, representando uma transformação da realidade através do entendimento e participação política dos cidadãos.

Em concordância com Silva et. al (2012a) o gerenciamento de resíduos está associado ao processo de conscientização da população referente aos padrões de consumo, da coleta seletiva e reaproveitamento de diversos materiais. Dessa forma, uma educação ambiental com enfoque nas políticas públicas de redução e destinação de resíduos é condição necessária em todos os municípios.

Este indicador pode ser avaliado como DESFAVORÁVEL, visto que no município não é comum a prática de atividades de educação ambiental, o que se reflete na falta de conhecimento por parte da população referente as questões ambientais. Durante a pesquisa, a gestão municipal afirmou apenas a ocorrência de palestras nas escolas. Importante destacar que esse tipo de atividade não é o suficiente para a construção de cidadãos de fato engajados nas questões ambientais, incluídas nestas o gerenciamento dos RSU, entretanto representa uma iniciativa que pode ser melhor desenvolvida, passando a instituir a educação ambiental como fator integrante na formação desde o início da vida escolar.

Providências para melhorias na destinação final dos resíduos. Como destacam Besen et al. (2017), com a implementação da PNRS, o previsto é que houvesse a eliminação de lixões, redução no número de aterros controlados e o aumento na quantidade de aterros sanitários até o ano de 2014. Contrariando o que se esperava, 1.998 municípios ainda realizam a disposição de seus resíduos em lixões e aterros controlados.

$$
\text { Alguns desafios estão }
$$

relacionados a gestão, sobretudo no que se refere a dificuldade de áreas para a disposição final dos resíduos e a grande quantidade de materiais recicláveis que são desperdiçados ao serem depositados em lixões (JACOBI, 2012).

De acordo com a gestão, muitas dificuldades são encontradas no tocante ao gerenciamento dos resíduos sólidos, particularmente quanto aos recursos disponíveis para o seu melhoramento. Verificou-se que existe uma proposta de implantação de um aterro sanitário para o município de Cachoeira dos Índios em parceria com cidades adjacentes, em decorrência da escassez de recursos. Entretanto, é notável que não existe uma devida preocupação com a destinação dos resíduos, bem como as consequências de um gerenciamento inadequado, fato verificado pela situação 
em que se encontra o lixão, o que avalia esse indicador como DESFAVORÁVEL.

Aplicação da PNRS. Locastro e De Angelis (2016), afirmam que na realidade o país dispõe de leis recentes relacionadas a disposição de resíduos, as quais estão essencialmente embasadas na Lei no 12.305/2010 da Política Nacional dos Resíduos Sólidos (PNRS), sendo que em todo o país encontra-se obstáculos financeiros para a sua efetiva aplicação. Diante disso, a implantação de aterros sanitários torna-se algo complexo, tendo em vista que um projeto bem elaborado e com um sistema eficiente requer um conjunto de fatores de segurança, que são inviáveis a municípios com escassez de recursos.

Neste sentido, o município da referida pesquisa enquadra-se no grupo de municípios que ainda não praticam efetivamente a PNRS, fato que pode ser verificado principalmente pelo não cumprimento da eliminação de lixões a céu aberto até o ano de 2014, conforme determinado pela lei. Diante o exposto, esse indicador avalia-se como DESFAVORÁVEL à sustentabilidade do município.

Existência de galpão para a separação dos resíduos. No vazadouro não é verificado nenhum tipo de galpão para a separação de materiais, os catadores selecionam os materiais de seu interesse e os dispõe em sacos para facilitar a condução destes. Portanto, esse indicador avalia-se como DESFAVORÁVEL, ao considerar que não há um espaço adequado para tal atividade, o que representa péssimas condições de trabalho para os catadores envolvidos e revela a despreocupação da gestão quanto à separação de materiais e sua posterior reutilização.

Prática da coleta seletiva.
Práticas como coleta seletiva,
implantação de aterros sanitários, entre
tantas ações, caracterizam-se como
providências mitigadoras. O problema

parte da geração, a qual todos somos responsáveis, devendo assim ter consciência da necessidade de diminuição de consumo e desperdícios, buscando o reaproveitamento dos materiais, de forma que o consumo seja consciente e viável (SILVA et al., 2012a)

A coleta seletiva consiste em um plano governamental de caráter ambiental, orçamentário e social, o qual proporciona melhorias de condições financeiras para os catadores incluídos nessa atividade (Lopes e Lopes, 2018).

Como destaca Silva e Lima (2018), essa prática sustentável aplica-se como um combate ao desperdício e uma busca pela preservação ambiental. Dentre os benefícios da coleta seletiva destaca-se a redução dos custos para a disposição final dos resíduos e reparação de áreas degradadas, bem como o prolongamento da vida útil dos aterros sanitários e melhorias para o município no âmbito das condições ambientais e de saúde pública. Ademais, essa atividade pode impulsionar a criação de cooperativas ou associações de catadores, gerando emprego e renda.

No Município de Cachoeira dos Índios não ocorre a prática da coleta seletiva, sendo os resíduos sólidos levados para o mesmo local sem uma separação. E ainda que em suas moradias, a população realize esse tipo de atividade, quando coletados os resíduos terão a mesma destinação. Diante o exposto, esse indicador avalia-se como DESFAVORÁVEL.

\section{Considerações finais}

0 gerenciamento inadequado dos resíduos sólidos é resultante da falta de conhecimento sobre as condições socioambientais, incluindo a não conscientização dos efeitos negativos ao ambiente advindos desse processo. 0 Munícipio de Cachoeira dos Índios não dispõe de um aterro sanitário, sendo os resíduos sólidos depositados em um 
lixão a céu aberto. Dessa forma, o gerenciamento não encontra-se de acordo com o estabelecido pela Política Nacional de Resíduos Sólidos, tendo a gestão e população civil pouco conhecimento sobre a problemática dos resíduos sólidos.

Através do Sistema de Indicadores de Sustentabilidade Pressão-Estado-Impacto-Resposta foram avaliados trinta e um indicadores, dos quais vinte e quatro foram classificados como desfavoráveis do ponto de vista da sustentabilidade. Esses dados revelam uma situação preocupante de insustentabilidade do município, que necessita da implementação de políticas públicas voltadas para um gerenciamento adequado dos resíduos sólidos urbanos.

\section{Conflito de interesses}

Os autores declaram não haver conflito de interesses.

\section{Referências}

Barbosa, E. A. Resíduos sólidos: aspectos conceituais e classificação. In: Barbosa, E. M; Batista, R. C.; Barbosa, M. F. N. (Orgs.). Gestão dos recursos naturais. Rio de Janeiro: Ciência Moderna, 2012. p. 169-210.

Besen, G. R.; Freitas, L.; Jacobi, R. P. Política Nacional de Resíduos Sólidos: implementação e monitoramento de resíduos urbanos. 1. ed. São Paulo: IEE USP: OPNRS, 2017.

Brasil. Lei no 6.938, de 31 de agosto de 1981. Dispõe sobre a Política Nacional do Meio Ambiente, seus fins e mecanismos de formulação e aplicação, e dá outras providências. Disponível em: <http://www.planalto.gov.br/ccivil_03/LEIS /L6938compilada.htm>. Acesso em: 21 mar. 2019.

Brasil. Lei no 12.305, de 02 de agosto de 2010. Institui a Política Nacional de Resíduos Sólidos; altera a Lei no 9.605, de 12 de fevereiro de 1998; e dá outras providências.. Disponível em: <http://www.planalto. gov.br/ccivil_03/_ato2007-2010/2010/lei/ l12305.htm>. Acesso em: 21 mar. 2019.
Cavalcante, L.P.S. Gestão integrada de resíduos sólidos e riscos que estão expostos catadores de materiais recicláveis. Campina Grande: Universidade Federal de Campina Grande, 2018. (Tese de doutorado em Recursos Naturais).

Cardoso, J. J.; Barros Júnior, A. P.; Pacheco, A. D. C. Desafios e possibilidades para gestão dos resíduos sólidos em consonância com a Lei n. 12.305/2010 no Município de IpojucaPE. In: El-Deir, S. G. E.; Pinheiro, S. M. G.; Aguiar, W. J. (Orgs.). Resíduos sólidos: práticas para uma gestão sustentável. 1. ed. Recife: EDUFRPE, 2016. p. 8-19.

Cunha, V.; Caixeta Filho, J. V. C. Gerenciamento da coleta de resíduos sólidos urbanos: estruturação e aplicação de modelo não-linear de programação por metas. Gestão e Produção, v. 9, n. 2, p. 143-161, 2002. https://doi.org/10.1590/S0104-530X 2002000200004

Godecke, M. V.; Naime, R. H.; Figueiredo, J. A. S. O consumismo e a geração de resíduos sólidos urbanos no Brasil. Revista Eletrônica em Gestão, Educação e Tecnologia Ambiental, v. 8, n. 8, p. 1700-1712, 2012. https://doi.org/ 10.5902/223611706380

Gouveia, N. Resíduos sólidos urbanos: impactos socioambientais e p perspectiva de manejo sustentável com inclusão social. Ciência \& Saúde Coletiva, v. 17, n. 6, p.1503-1510, 2012. https://doi.org/ 10.1590/S1413-81232012000600014

Hanai, F.Y. Sistema de indicadores de sustentabilidade: uma aplicação ao contexto de desenvolvimento do turismo na região de Bueno Brandão, Estado de Minas Gerais, Brasil. São Paulo: Universidade de São Paulo, 2009. (Tese de doutorado).

Hoefel, M. G.; Carneiro, F. F.; Santos, L. M. P.; Gubert, M. B.; Amate, E. M.; Santos, W. Acidentes de trabalho e condições de vida de catadores de resíduos sólidos recicláveis no lixão do Distrito Federal. Revista Brasileira de Epidemiologia, v. 16, n. 3, p. 764-785, 2013. https://doi.org/10.1590/S1415-790X 2013000300020

IBGE - Instituto Brasileiro de Geografia e Estatística. Brasil - Paraíba - Cachoeira dos Índios. 2010. Disponível em: <https://cidades.ibge.gov.br/brasil/pb/cach oeira-dos-indios >. Acesso em: 21 mar. 2019. 
Jacobi, P. R. Desafios e reflexões sobre resíduos sólidos nas cidades brasileiras. In: Santos M. C. L.; Gonçalves-Dias, S. L. F. (Orgs.). Resíduos sólidos urbanos e seus impactos socioambientais. São Paulo: IEE-USP, 2012.

Leite, A. L.; Barros, J. D. S. Avaliação da sustentabilidade socioambiental no gerenciamento de resíduos sólidos no Município de São José de Piranhas, Estado da Paraíba, Nordeste do Brasil. Revista Brasileira de Gestão Ambiental e Sustentabilidade, v. 6, n. 14, p. 713-731, $2019 . \quad$ https://doi.org/10.21438/rbgas. 061407

Lima, A. K. T. Principais pontos da Política Nacional de Resíduos Sólidos para a gestão de resíduos municipais. In: El-Deir, S. G. Resíduos Sólidos: perspectivas e desafios para a gestão integrada. 1. ed. Recife: EDUFRPE, 2014. p. 20-28.

Lopes, G. A. B.; Lopes, R. L. A gestão dos resíduos sólidos urbanos do Município de Parnamirim-RN. Revista Gestão \& Sustentabilidade Ambiental, v. 7, n. 2, p. 22-43, 2018. https://doi.org/10.19177/ rgsa.v7e2201822-43

Moreira, R. S. Contribuições do sistema de indicador de sustentabilidade PressãoEstado-Impacto-Resposta (P-E-I-R) na análise situacional do gerenciamento dos resíduos sólidos urbanos em Aurora-CE. Cajazeiras: Universidade Federal de Campina Grande, 2016. (Monografia de Licenciatura em Ciências Biológicas).

Moreira, R. S.; Barros, J. D. S.; Silva, J. L. A.; Araújo, J. T.; Pordeus, A. V. Sustentabilidade socioambiental no gerenciamento de resíduos sólidos urbanos: estudo de caso com aplicação do modelo Pressão-EstadoImpacto-Resposta. Revista Espacios, v. 38, n. 58, p. 1-5, 2017. Disponível em: <https://www.revistaespacios.com/a17v38n 58/a17v38n58p05.pdf>. Acesso em: 21 mar. 2019.

Pedrosa, D. S. F.; Nishiwaki, A. A. M. Resíduos sólidos: uma visão prospectiva a partir da análise histórica da gestão. In: El-Deir, S. G. E.; Pinheiro, S. M. G.; Aguiar, W. J. (Orgs.). Resíduos Sólidos: perspectivas e desafios para a gestão integrada. 1 ed. Recife: EDUFRPE, 2014. p. 12-18.

Pereira, S. S.; Curi, R. C. Modelos de gestão integrada dos resíduos sólidos urbanos: a importância dos catadores de materiais recicláveis no processo de gestão ambiental. In: Lira, W. S.; Cândido, G. A. (Orgs.). Gestão sustentável dos recursos naturais: uma abordagem participativa. Campina Grande: EDUEPB, 2013, p. 149-172.

Prodonov, C. C.; Freitas, E. C. Metodologia do trabalho científico: métodos e técnicas da pesquisa e do trabalho acadêmico. 2. ed. Novo Hamburgo: Feevale, 2013.

Ronilk, R. Resíduos sólidos urbanos: repensando suas dimensões. In: Santos, M. C. L.; Gonçalves-Dias, S. L. F. (Orgs.). Resíduos sólidos urbanos e seus impactos socioambientais. São Paulo: IEE-USP, 2012.

Silva, A. F. G.; Lima, R. A. A. A coleta seletiva nas universidades: o caso da Universidade Regional do Cariri/URCA. In: Cirne, L. E. M. R. (Org.). Gestão integrada de resíduos: universidade \& comunidade. Campina Grande: EPGRAF, 2018. v. 1. p. 18-22.

Silva, E. L.; Menezes, E. M. A pesquisa e suas classificações. In: Silva, E. L.; Menezes, E. M. Metodologia da pesquisa e elaboração de dissertação. Florianópolis: UFSC, 2005. p. 19-23.

Silva, S. S. F.; Cândido, G. A.; Ramalho, A. M. C. Diagnóstico situacional dos resíduos sólidos urbanos no Município de Cuité-PB: uma aplicação do sistema de indicador de sustentabilidade pressão - estado - impacto resposta (p-e-i-r). Revista Gestão Industrial, v. 8, n. 3, p. 72-90. 2012a. https://doi.org/10.3895/S1808-0448 2012000300003

Silva, S. S. F.; Santos, J. G.; Cândido, G. A.; Ramalho, A. M. C. Indicador de Sustentabilidade Pressão - Estado - Impacto Resposta no diagnóstico do cenário sócio ambiental resultante dos resíduos sólidos urbanos em Cuité-PB. REUNIR - Revista de Administração, Contabilidade e Sustentabilidade, v. 2, n. 3, p. 76-93, 2012b. https://doi.org/10.18696/reunir.v2i2.68 
Soares, A. M.; Barros, J. D. S.; Bezerra, D. S. Aplicação do Sistema de Indicadores de Sustentabilidade Pressão-Estado-ImpactoResposta (PEIR) no Município de Nazarezinho-PB: enfoque no estado dos resíduos sólidos. Revista Brasileira de Gestão Ambiental e Sustentabilidade, v. 4, n. 8, p. 255-262, 2017. https://doi.org/ $10.21438 /$ rbgas. 040802

\footnotetext{
CC Informação da Licença: Este é um artigo Open Access distribuído sob os termos da Licença Creative Common Attribution, que permite uso irrestrito, distribuição e reprodução em qualquer meio, desde que a obra original seja devidamente citada.
} 